\title{
Whooping cough in relation to other childhood infections in 1977-9 in the United Kingdom
}

\author{
GORDON T. STEWART
}

From the Department of Community Medicine, University of Glasgow

SUMMARY Estimates based upon notifications indicate that there was in the 1977-9 triennium in the United Kingdom the largest outbreak of whooping cough for 20 years or more. During this triennium there was also a sharp increase in other infectious diseases of childhood, notably in non-notifiable respiratory infections. Isolates of certain respiratory viruses ran in parallel and collectively outnumbered those of Bordetella pertussis during the period of increase in notifications. There was highly significant positive correlation between isolates of $B$ pertussis and of ECHO viruses, of Mycoplasma pneumoniae and rhinoviruses and, in Scotland only, of Coxsackie virus. Deaths in which whooping cough was certified as the immediate or underlying cause were lower than in previous outbreaks. Only a minority were bacteriologically confirmed.

A closer study of the outbreak in Glasgow disclosed considerable variations in notification procedure and lack of correlation with isolates of $B$ pertussis at the peak of the notification period. Attack rates calculated from notifications were higher in deprived areas. Birth cohort studies showed a significantly higher proportion of notifications in unvaccinated children aged $1-4$ and this was confirmed in family studies of clinical whooping cough in home contacts. But, overall, about $35 \%$ of reported cases were children who had received three injections of triple vaccine. Acceptance of pertussis vaccine fell sharply in 1975 but about $95 \%$ of unvaccinated children in age groups $0-5$, including the 1977 and the 1977 and 1978 birth cohorts, either escaped infection or were not notified.

Whooping cough, in common with some other highly communicable diseases of childhood, has decreased in severity more or less continuously during the present century. This includes the period during which antimicrobial agents and pertussis vaccine came into general use. It is assumed by most health authorities $^{1}$ that mass vaccination, which began in 1958 in the United Kingdom, is mainly responsible for the improvement. In previous studies, ${ }^{2-4}$ I have questioned this assumption because it appeared from these and other studies ${ }^{5-17}$ that pertussis vaccine was not very effective. I suggested also that secular, social, and demographic variables were dominant factors in the decline in morbidity of this disease, and that vaccination carried neurotoxic risks which might outweigh its benefits. ${ }^{34}$

These conclusions were based on studies of epidemiological trends between 1900 and 1978 and on some personal investigations in Glasgow between 1973 and 1978. The present report deals with occurrences between 1977 and 1979 because during that time there was an increase in notifications of whooping cough throughout the United Kingdom ${ }^{7-10}$ and a fall in vaccine acceptance.

\section{Methods}

The methods used in my studies in Glasgow are essentially those reported in previous publications. $2-4$ I have also obtained from the Office of Population Censuses and Surveys (OPCS) in England and from the Registrar General in Scotland copies of any death certificates in which whooping cough was listed as a main or contributory cause. Because whooping cough, like certain other highly communicable infections, shows cyclical rather than seasonal trends, it is necessary to look at current events in the perspective of previous outbreaks. For this purpose, I have used notifications and vaccination returns, supplied by the OPCS, the Department of Health and Social Security, the Scottish Home and Health Department, the Registrars General, and the Research Unit of the Royal College of General Practitioners (RCGP). National figures for isolates of 


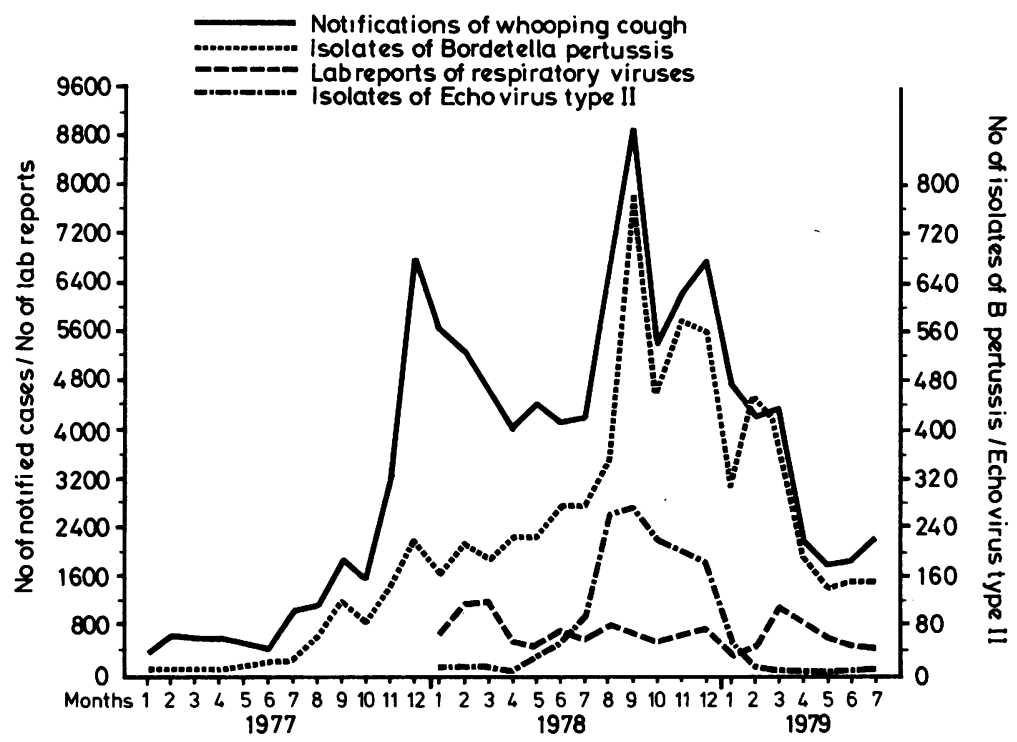

Fig. 1 Whooping cough: England and Wales 1977-9.

$B$ pertussis and respiratory viruses were obtained from the weekly reports (CDR) of the Public Health Laboratory Service (PHLS) at Colindale and the Communicable Diseases (Scotland) Unit (CDS) at Ruchill Hospital.

\section{Results}

NOTIFICATIONS

In England and Wales, notifications began to increase in 1977. This continued through 1978-9, amounting to 114557 cases in the triennium-the largest number of notifications since 1957-8, when the national vaccination programme began. Unlike previous outbreaks, there were three distinct peaks in this triennium. The second and third peaks, but not the first, coincided with peak isolates of $B$ pertussis (Fig. 1) as reported in CDR. The 1978 peak coincided also with an outbreak of type 11 ECHO virus infection and there was, during the entire period, an increase in all forms of respiratory infection as indicated by isolates of respiratory viruses by the PHLS and by returns from the Research Unit of the RCGP, as reported in the weekly reports of the OPCS. Correlations of weekly isolates of $B$ pertussis with ECHO virus (all types and type 11), with rhinoviruses, and especially with M pneumoniae $(\mathrm{r}=0.96)$ were statistically significant (Table 1).

In Scotland, notifications in 1977-9 were about twice those in 1973-5 and marginally higher than those in 1969-71. The duration of the period of

Table 1 Correlations between isolates of B pertussis, respiratory viruses and M pneumoniae in the UK, January 1977-July 1979

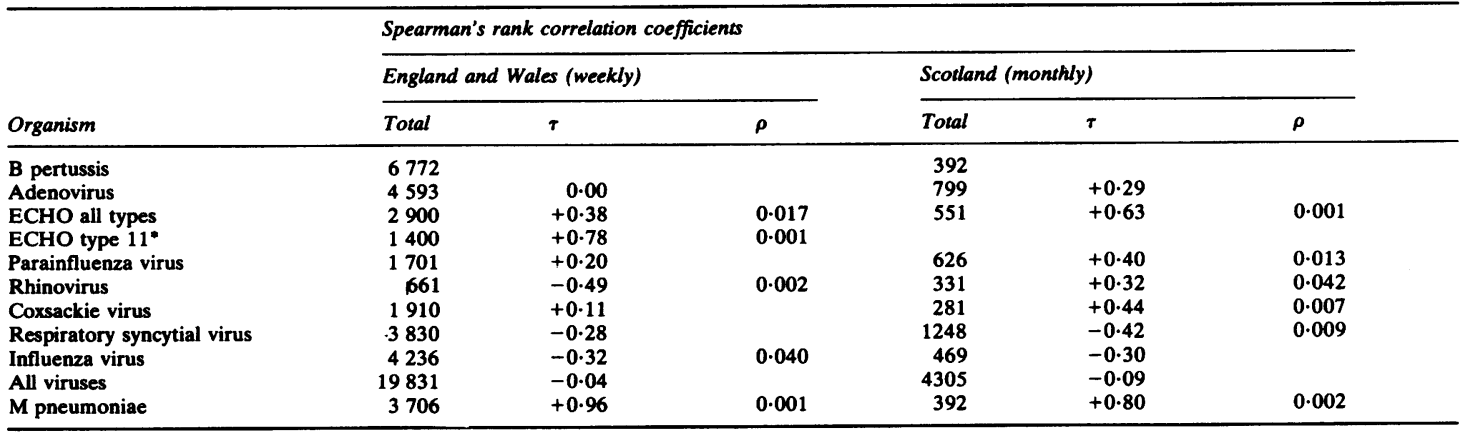

"January 1978-July 1979. 


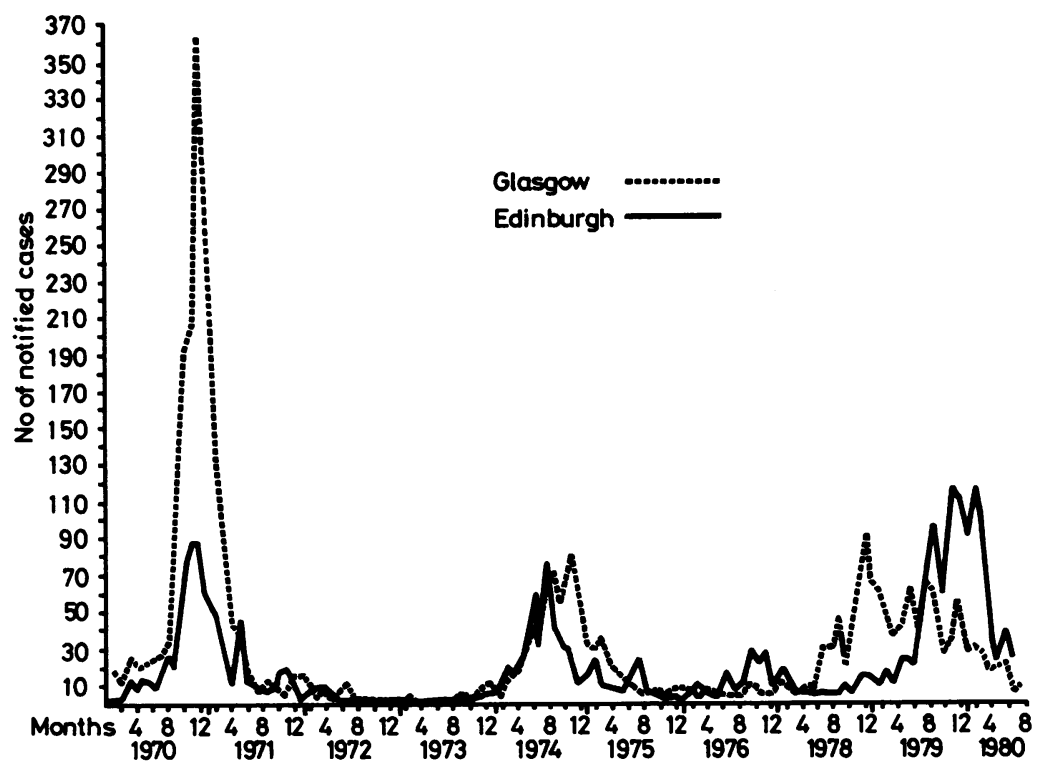

Fig. 2 Notifications of whooping cough in Glasgow and Edinburgh 1970-80.

increased notification in 1977-9 (82 weeks) was longer than any since 1966-8 (88 weeks) but the relative numbers were lower than in England and Wales. Notifications in Glasgow (1049) were roughly parallel to those in Scotland as a whole. The duration of the interepidemic period, as estimated by the intervals between the months of peak notifications since 1967 in Scotland, was relatively constant at 44-46 months. Peak notifications coincided with this interval in Edinburgh but not in Glasgow, where the outbreak started sooner and persisted longer in a very unusual, irregular fashion (Fig. 2). There was, as in England and Wales, an unusual double peak not apparent in any other outbreak of whooping cough since 1900 . Isolations of $B$ pertussis did not increase appreciably in Scotland until August 1978, that is, nine months after the peak of notifications. Other respiratory infections were also very prevalent during the period, as estimated by isolates of respiratory viruses reported by CDS which increased in children during the early months of 1978 when adeno-, parainfluenza and respiratory syncytial (RS) viruses individually outnumbered isolates of $B$ pertussis. M pneumoniae and ECHO virus began to increase in parallel with $B$ pertussis in August 1978 and did not decrease until June 1979 , when isolates of $B$ pertussis decreased simultaneously. There were some highly significant positive correlations between

Table 2 Attack rate and immunisation status of notified cases of whooping cough in Glasgow in 1978 by birth cohorts

\begin{tabular}{|c|c|c|c|c|c|c|}
\hline \multirow[b]{2}{*}{ Year of birth } & \multicolumn{4}{|c|}{ Immunisation status } & \multirow[b]{2}{*}{ Total } & \multirow{2}{*}{$\begin{array}{l}\text { Attack rate } \\
\text { per } 1000\end{array}$} \\
\hline & Complete & Incomplete & Not immunised & Unknown & & \\
\hline $\begin{array}{l}1978 \\
1977 \\
1976 \\
1975 \\
1974 \\
1973 \\
1972 \\
1971 \\
1970 \\
\text { pre } 1970\end{array}$ & $\begin{array}{r}2 \\
4 \\
21 \\
22 \\
20 \\
17 \\
21 \\
24 \\
19 \\
20\end{array}$ & $\begin{array}{r}5 \\
14 \\
7 \\
0 \\
4 \\
3 \\
1 \\
2 \\
0 \\
0\end{array}$ & $\begin{array}{r}45 \\
61 \\
41 \\
18 \\
13 \\
23 \\
7 \\
10 \\
3 \\
16\end{array}$ & $\begin{array}{r}2 \\
14 \\
14 \\
9 \\
12 \\
8 \\
19 \\
15 \\
8 \\
21\end{array}$ & $\begin{array}{l}54 \\
93 \\
83 \\
49 \\
49 \\
51 \\
48 \\
51 \\
30 \\
57\end{array}$ & $\begin{array}{l}4.4 \\
7 \cdot 7 \\
6 \cdot 6 \\
3.5 \\
3.4 \\
3.8 \\
3.5 \\
3.3 \\
1.8 \\
0.6\end{array}$ \\
\hline $\begin{array}{l}\text { Total } \\
\text { (All ages) }\end{array}$ & $\begin{array}{l}170 \\
30 \%\end{array}$ & $\begin{array}{l}36 \\
6 \cdot 4 \%\end{array}$ & $\begin{array}{l}237 \\
42 \%\end{array}$ & $\begin{array}{l}122 \\
21 \cdot 6 \%\end{array}$ & 565 & $5 \cdot 3$ \\
\hline
\end{tabular}


monthly isolates of $B$ pertussis and ECHO, parainfluenza, Coxsackie, rhinovirus, and $M$ pneumoniae during the period (Table 1).

Since isolates of $\boldsymbol{B}$ pertussis increased appreciably in 1978 in Glasgow, that year was chosen for a study of birth cohorts (Table 2). The overall attack rate was 5.3 per 1000 . The highest rate of notification was in the cohort of infants born in 1977, in whom the attack rate was $7 \cdot 7$ per 1000 . In the cohorts born in 1973-6, $34 \%$ of cases occurred in children with authenticated records of complete (DPT $\times 3$ ) vaccination as compared with $47 \%$ in those with incomplete and with no vaccination. Records could not be traced in $19 \%$. The overall attack rate in these cohorts was 4.3 per 1000. The cohorts born before 1973 had an overall attack rate of 1.7 per 1000 with $45 \%$ of cases in fully vaccinated children.

Vaccine acceptance in the vulnerable 1976 birth cohort was $58 \%$ and the overall attack rate in this cohort was 6.6 per 1000 . If it is assumed that the risk of exposure was equal in all children, the observed rate in the vaccinated cohort was lower than that in the unvaccinated. The difference is statistically significant (Table 3 ) but before practical significance

Table 3 Notified whooping cough in 1978 in 1976 birth cohort in Glasgow (expected figures in brackets)

\begin{tabular}{lllrl}
\hline \multicolumn{4}{c}{ WHOOPING COUGH } & Autack rate \\
\cline { 2 - 4 } & Yes & No & per 1000 \\
\hline Vaccinated & $29(48)$ & 7221 & 7250 & 4.0 \\
Not vaccinated & $54(35)$ & 5239 & 5250 & 10.3 \\
& 83 & 12460 & 12543 & 6.6 \\
\hline
\end{tabular}

Relative risk 0.39

$\chi^{2}=18.2$ p 0.01 . can be ascribed to this difference, it is appropriate to note the low attack rate, even in the unvaccinated children, the significantly higher distribution of cases in districts with an excess of Social Classes IV and V (Table 4), and the lower acceptance rate of all vaccines and other routine aspects of child care in these districts. There was also, as in a previous study, ${ }^{4}$ a significantly greater likelihood of children with a cough who were unvaccinated than of vaccinated children being notified as whooping cough. These considerations also apply to hospital admissions. In Glasgow in 1977-8 these numbered 184 (18\% of notified cases) of whom 95 (52\%) were infants. $B$ pertussis was isolated from $60(33 \%)$. There were no deaths. We have no evidence at present of permanent pulmonary or cerebral sequelae in cases admitted and discharged in 1974-5 or in a shorter follow-up at present of 200 more recent cases.

Secondary attack rates were studied in 153 households in each of which a credible 'introducer' of infection had been identified during the period in 1978 when isolates of $B$ pertussis increased in Glasgow. These were 146 children and seven adults who had been notified independently by a practitioner and who had the following features accepted in the 1951 Medical Research Council study ${ }^{5}$ and in a more recent American study ${ }^{8}$ as being appropriate for a clinical diagnosis of whooping cough: catarrhal symptoms followed by paroxysmal cough with or without vomiting or cyanosis for two weeks or more, the patient being well between paroxysms.

The results (Table 5) showed a high secondary attack rate $(69 \%-72 \%)$ in children under 5 , dropping sharply at later ages. If primary cases were included,

Table 4 Attack rate of whooping cough in 1978 by social classes of addresses of notified cases in three sets of five postcode districts in Glasgow

\begin{tabular}{|c|c|c|c|c|}
\hline Postcodes (G) & $\begin{array}{l}\text { Total births as } \% \\
\text { total deaths }\end{array}$ & $\begin{array}{l}\% \text { in Social Classes } \\
I V \text { and } V\end{array}$ & $\begin{array}{l}\text { Deprivation index } \\
(\%)\end{array}$ & $\begin{array}{l}\text { Pertussis } \\
\text { notifications (1000) }\end{array}$ \\
\hline $\begin{array}{l}15,33,34,45,53 \\
31,44,46,72,73 \\
11,41,42,43,44\end{array}$ & $\begin{array}{r}197 \\
140 \\
94\end{array}$ & $\begin{array}{l}45 \\
26 \\
15\end{array}$ & $\begin{array}{r}48 \\
10 \\
5\end{array}$ & $\begin{array}{ll}1.9 & (1.5-2.7)^{* *} \\
1.0 & (0.4-1.4) \\
0.6 & (0.3-1.3)\end{array}$ \\
\hline
\end{tabular}

"Calculated from demographic indicators (Strathclyde Regional Council 1974-76).

* (Range) in children.

Table 5 Secondary attack rates in children exposed to whooping cough in 147 families visited in Glasgow in 1978-9. The table excludes the child in the family who contracted whooping cough first

\begin{tabular}{|c|c|c|c|c|c|c|c|c|c|}
\hline \multirow[b]{2}{*}{$\begin{array}{l}\text { Age group } \\
\text { (years) }\end{array}$} & \multicolumn{3}{|c|}{ Vaccinated $(D T P \times 3)$} & \multicolumn{3}{|c|}{ Not vaccinated $(D T P 0 /<2)$} & \multirow[b]{2}{*}{$\begin{array}{l}\text { Total } \\
\text { attacked }\end{array}$} & \multirow[b]{2}{*}{$\begin{array}{l}\text { Total } \\
\text { at risk }\end{array}$} & \multirow[b]{2}{*}{$\begin{array}{l}\text { Overall attack } \\
\text { rate per } 1000\end{array}$} \\
\hline & Attacked & $\begin{array}{l}\text { Not } \\
\text { attacked }\end{array}$ & Rate & Attacked & $\begin{array}{l}\text { Not } \\
\text { attacked }\end{array}$ & Rate & & & \\
\hline $\begin{array}{l}\text { Under } 1 \\
1-5 \\
6-15 \\
0-15\end{array}$ & $\begin{array}{r}0 \\
19 \\
27 \\
46\end{array}$ & $\begin{array}{r}1 \\
23 \\
114 \\
138\end{array}$ & $\begin{array}{r}0 \\
452 \\
191 \\
250\end{array}$ & $\begin{array}{r}13 \\
34 \\
9 \\
56\end{array}$ & $\begin{array}{r}4 \\
1 \\
28 \\
33\end{array}$ & $\begin{array}{l}765 \\
971 \\
240 \\
629\end{array}$ & $\begin{array}{r}13 \\
53 \\
36 \\
102\end{array}$ & $\begin{array}{r}18 \\
77 \\
178 \\
273\end{array}$ & $\begin{array}{l}722 \\
688 \\
202 \\
374\end{array}$ \\
\hline
\end{tabular}

$x^{2}(4 d f)=22 \quad p<0.001$. 
the figures showed, as in Glasgow as a whole, peaks in the first two years of life, then again at ages 4-5, as if many infections were acquired in playgroups, nurseries, and the first year of school. The highest secondary attack rate (72\%) was in infants. Of children under $5,55 \%$ had been vaccinated, and the secondary attack rate in this group was significantly lower $(p<0.01)$ than in the unvaccinated. The number of cases in unvaccinated or incompletely vaccinated children among the older children was also significantly lower, but the overall secondary attack rate was $37 \%$, with $45 \%$ of cases occurring in fully vaccinated children. On the assumption that vaccination might be serving partly as an index of better child care, we analysed our groups according to the condition and crowding index of the household, but this did not disclose any significant excess of infection or of unvaccinated children in families in substandard houses-in contrast to what we found in 1974- $5^{23}$ and to the distribution of cases in Glasgow generally (Table 4).

Of the 419 children in these homes, 13 aged under 3 were reported as having had severe sequelae after vaccination: four with seizures, one of whom, with repeated convulsions, was admitted to hospital; the others had vomiting or diarrhoea, or both, screaming, and fever. Seven of these children contracted whooping cough. In 10 others, vaccination was incomplete because of lesser reactions. The overall vaccination rate in Glasgow during 1975-8 was 54\% $(51 \%-58 \%)$ in infants and $12 \%$ in older, previously unvaccinated children.

\section{DEATHS}

Information was obtained from the OPCS, from the Registrar General in Scotland, and from clinicians, pathologists, and coroners concerning 31 deaths in the United Kingdom in which whooping cough was certified as the immediate or underlying cause. Twenty-one of these deaths occurred at under six months; four of the 21 had major congenital lesions. Of the 10 deaths at ages over one year, five had major congenital or other lesions. $B$ pertussis was isolated from six of the 31 children, during life or in post-mortem examinations. Two of the deaths, both at about one month, were in Scotland. B pertussis was not isolated but the clinical features were compatible with whooping cough. Only one death in Glasgow since 1971 was attributed to whooping cough. This was an infant aged six months admitted to hospital because of congenital cardiac lesion and episodes of cardiac arrest. $B$ pertussis was not isolated.

NOTIFICATIONS IN PRACTICE The pattern of corrected notifications in Glasgow was examined by comparing those received with school absences, secondary cases, and distribution of cases and of general practitioners. There were no notifications, or only a few, from several districts. The majority of notifications, school absences, and secondary cases were in peripheral new housing estates but many notifications were also received from districts populated by Social Classes I and II. About 650 general practitioners were registered in Glasgow in 1977-9, of whom only $117(18 \%)$ notified the 1049 cases. Three hundred and eighty-eight cases (37\%) were notified by 13 practitioners (2\%), each of whom notified nine or more cases, and four notified 15 or more. Several cases were notified twice and many cases admitted to hospital were not notified.

\section{OTHER INFECTIONS}

Notifications for measles and scarlet fever also increased in the United Kingdom during 1977-9. According to regular notifications, the number of cases of measles (378 118) was rather more than twice that of whooping cough, but returns of the Research Unit of the RCGP, as reported by the OPCS, indicated higher rates for measles and much higher rates for rubella, chickenpox, and mumps. In Glasgow, the rate for measles in children was at least thrice that for whooping cough. Acceptance rates for measles vaccine in children aged $1-3$ were above $50 \%$ during the period $1973-8$, but in contrast to whooping cough, there were very few notified cases of measles in vaccinated children. Rubella rates in 1978 and 1979 were much higher. The outbreak in 1979 was by far the largest in 30 years and had a rate of notification which, in Glasgow, was 20 times that of whooping cough. Acceptance of rubella vaccine in girls aged $11-13$ was about $80 \%$ and very few cases were reported in vaccinated girls. The totality of notifications and RCGP returns indicates that infections of childhood were more prevalent in 1978-9 than for many years previously.

\section{Discussion}

In so far as reliance can be placed upon notifications, there was in the 1977-9 triennium the most extensive outbreak of whooping cough in the United Kingdom since 1957. There was also during this period an increase in many forms of respiratory infection in children with an increase in isolates of $B$ pertussis as well as, and simultaneously with, a range of other respiratory pathogens.

Since notifications increased during a period when acceptance of pertussis vaccine decreased, it has been reported $^{7-9}$ or assumed ${ }^{10} 11$ that this was the reason for the outbreak. The present study supports this belief in so far as whooping cough was significantly 
less frequent in recently vaccinated home contacts aged 1-4 of a sample of notified cases. But it was also found, as in previous reports, ${ }^{2-412}$ that infants and older children were not protected by the present vaccination programme and that, both in domestic surveillance and in notifications, 35-46\% of cases occurred in children who had received three injections of triple vaccine. The 31 deaths ascribed to whooping cough during the triennium were mainly in infants, usually unconfirmed or associated with other lesions or disadvantages. Even so, the death rate in relation to notifications was the lowest on record.

The occurrence of whooping cough in vaccinated children has been explained by the Joint Committee on Vaccination and Immunisation ${ }^{1}$ and by Church $^{\mathbf{9}}$ as being inevitable in a highly vaccinated population. The calculations and mathematical model used in these explanations make two assumptions, (a) that vaccination is the only independent variable in an obviously complex situation and (b) that currently used vaccines confer $90 \%$ overall protection. The first assumption is invalid because of the absence of whooping cough in exposed, unvaccinated children and the variation in attack rate in time and place; the second by begging the question at issue and by the fact that $90 \%$ overall protection has never been established except in certain segments of the MRC trials carried out in $1951-6 . .^{513}$ The national vaccination programme based on those trials did not prevent recurrence of whooping cough cyclically in the United Kingdom. Vaccines used between 1957 and 1968 were found to be only marginally protective. ${ }^{12}$ Deaths of children with whooping cough fell to a low level before the national vaccination programme began and have not fallen appreciably since then, except in the present outbreak.

Recent reports from elsewhere ${ }^{14}{ }^{15}$ make it clear not only that whooping cough can occur in highly vaccinated populations but also that reduction of vaccination, as in West Germany, ${ }^{1617}$ does not necessarily lead to recurrence of outbreaks or to a rise in mortality. In Egypt, it is recorded ${ }^{19}$ that notifications and mortality fell continuously from 1950 in a population which was largely unvaccinated until 1974. In recent outbreaks in the USA ${ }^{19}$ and Canada $^{20}$ substantial proportions of cases occurred in vaccinated children.

In assessing the rise and fall of any communicable disease, it is essential to examine its background of secular and cyclical trends. Historically, the dominant and obvious fact is that most, if not all, major communicable diseases of childhood have become less serious in all developed countries for 50 years or more. Whooping cough is no exception. It has behaved in this respect exactly like measles (Fig. 3 ) and similarly to scarlet fever and diphtheria, in

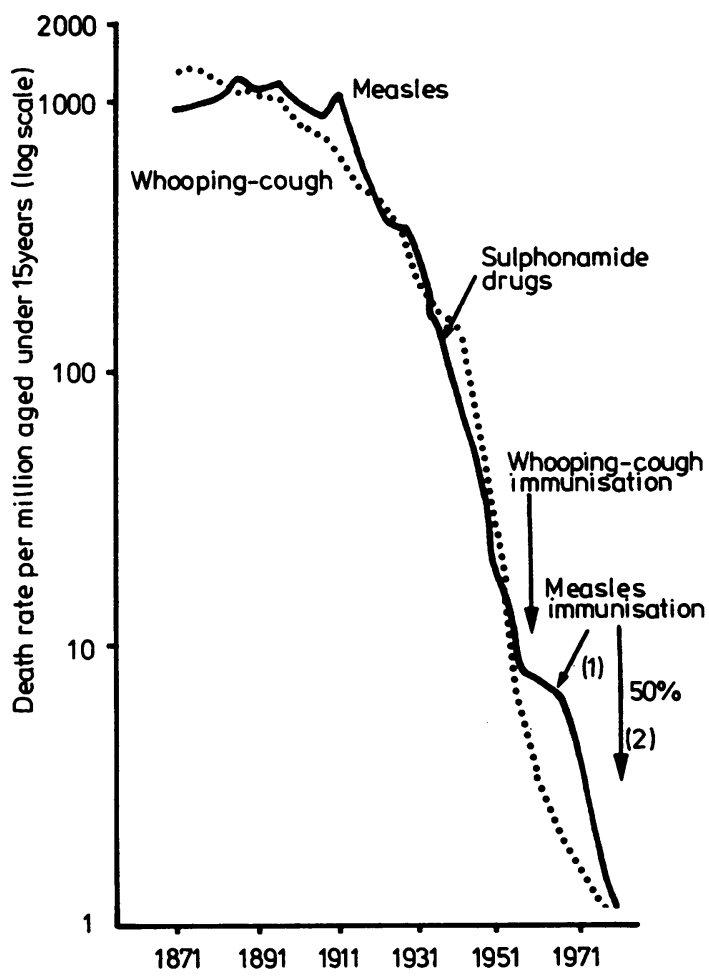

Fig. 3 Childhood mortality from measles and whooping cough: England and Wales 1871-1971.

each of which at least $80 \%$ of the total decline in mortality, since records began to be kept in the United Kingdom in 1860, occurred before any vaccines or antimicrobial drugs were available and $90 \%$ or more before there was any national vaccine programme. These facts establish beyond doubt the governing role of non-specific, environmental, personal, and secular variables in these infections. The increase in whooping cough in the United Kingdom has been accompanied by increases in measles, mumps, scarlet fever, chickenpox, respiratory viral infections and, notably, in rubella, in an epidemic which is the largest for $\mathbf{3 0}$ years.

Two further studies are relevant. The first, by the Resiearch Unit of the Royal College of General Practitioners in Swansea, ${ }^{21}$ reports an outbreak in Glamorgan of 2295 cases in 1977-9 in a population of 360000 in whom acceptance of triple vaccine had fallen from $38 \%$ in 1973 to $9.5 \%$ in 1974 and about $14 \%$ in 1976 . The attack rate, based on notifications, was 6.4 per 1000 -about seven times higher than that reported in Glasgow during the same period. Bacteriologically proven cases numbered $905(39 \%)$ which was also higher than the rate $(33 \%)$ in cases 
admitted to hospital in Glasgow. However, the secondary attack rate (all ages) in households was $40 \%$ compared with $37 \%$ in Glasgow, and the relative risk of whooping cough in vaccinated children was 0.41 , as against 0.40 in Glasgow. In children under 5 , the relative risk in Glamorgan was 0.51 , in Glasgow 0.48 . The authors attribute the extent of the outbreak in Glamorgan to the fall in vaccine acceptance but it is obvious from the above that, even if no allowance is made for other variables, the protective effect of pertussis vaccine is no higher in Glamorgan than in Glasgow, that the effect is at best partial in younger children and insignificant in older children. The Swansea unit claims that the disease was milder in vaccinated children but gives no data to substantiate this claim. It claims that the extent of the outbreak, in Glamorgan as in England and Wales generally, was due to the fall in vaccine acceptance, but this claim is based not on evidence but on data prepared by the Department of Health and Social Security which were wrongly analysed."

The second report ${ }^{22}$ shows that hospital admissions in the Oxford Region in 1974-9 rose proportionately and significantly with notifications, and that there

\section{References}

'Joint Committee on Vaccination and Immunisation. Whooping Cough Vaccination: Review of Evidence. London: HMSO, 1979.

${ }^{2}$ Bassili WR, Stewart GT. Epidemiological evaluation of immunisation and other factors in the control of whooping cough. Lancet 1976; i: 471-3.

${ }^{3}$ Stewart GT. Vaccination against whooping cough : efficacy versus risks. Lancet 1977; i: 234-7.

'Stewart GT. Pertussis vaccine: the United Kingdom's experience. In: New Developments Pertussis. Manclark CR, Hill JC, ed. Tunbridge Wells: Castle House Publications, 1978: 262-78.

s Medical Research Council. The prevention of whooping cough by vaccination. $B R$ Med J 1951; i: 1463-71.

-Baraff LJ, Wilkins J, Wehrle PF. The role of antibiotics, immunisation and adenoviruses in pertussis. Pediatrics 1978; 61: 224-30.

'Jenkinson D. Outbreak of whooping cough in general practice. $\mathrm{Br}$ Med J 1978; ii: 577-8.

-Stuart-Harris CH. Experiences of pertussis in the United Kingdom. In: New Developments in Pertussis. Manclark CR, Hill JC, ed. Tunbridge Wells: Castle House Publications, 1978: 256-61.

'Church MA. Evidence of whooping cough vaccine efficacy from the 1978 whooping cough epidemic in Hertfordshire. Lancet 1979; ii: 188-90.

${ }^{10}$ Minerva. Views. Br Med J 1980; 280: 945.

"Koplan JP, Schoenbaum SC, Weinstein MC. Correspondence. N Engl J Med 1980; 302: 634.

${ }_{12}$ Public Health Laboratory Service. Efficacy of whooping cough vaccines before 1968. Br Med J 1973; i: 259-62.

${ }_{13}$ Medical Research Council. Vaccination against whooping cough. Final report. Br Med J 1959; i: 994-1000.

${ }^{14}$ Bennett NM. Whooping cough in Melbourne. Med J Aust 1973; 2: 481-7.

${ }^{15}$ Ditchburn RK. Whooping cough after stopping pertussis immunisation. Br Med J 1979; i: 4601-3. was a significant increase in the 1978 peak compared with that of 1974 . This is taken to indicate that the increase in notifications represents a true increase of whooping cough rather than of other respiratory infections, but no data are offered to show the relationship to isolates of $B$ pertussis and other respiratory pathogens.

In the face of these facts, the place of vaccination in the control of whooping cough is debatable. The value of a temporary and partial protective effect has to be weighed against the undoubted toxicity of pertussis vaccine, causing unpredictable reactions which are not only very frequent ${ }^{23-26}$ but which are sometimes irreversibly damaging to the life of the child and its family. ${ }^{16} 232728$ In the United Kingdom and in many other countries, whooping cough (and measles) are no longer important as causes of death or severe illness except in a small minority of infants who are usually otherwise disadvantaged. In these circumstances, I cannot see how it is justifiable to promote mass vaccination of children everywhere against diseases which are generally mild, which confer lasting immunity, and which most children escape or overcome easily without being vaccinated.

${ }^{16}$ Ehrengut $W$. Whooping cough vaccination. Lancet 1976 ; i: 370 .

${ }^{17}$ Ehrengut W. Lässt sich die Reserve gegenüber der Pertussis schutzimpfung begrüden? Pediatr Prax 1980; 23: 3-13.

${ }^{18}$ Bassili WR. Studies on the epidemiology and control of whooping cough. Ph D thesis. Glasgow : University of Glasgow, 1977.

${ }^{19}$ US Department of Health, Education and Welfare. Pertussis, Georgia. Morbidity and Mortality Weekly Reports No. 26. Atlanta: Center for Disease Control, 1977: 307-8.

${ }^{20}$ Matthias RG. Whooping cough in spite of immunisation. Can J Public Health 1978; 69: 130-2.

${ }^{21}$ Royal College of General Practitioners Swansea Research Unit. Practice research. Br Med J 1981; 282: 23-30.

${ }^{22}$ Goldacre MJ, Harris RI. Hospital admissions for whooping cough in the Oxford Region, 1974-9. Br Med J 1981; 282: 106-7.

${ }^{23}$ Strom J. Further experience of reactions especially of a cerebral nature in conjunction with triple vaccination. Br Med J 1967; iv: 320-2.

"Perkins FT, Sheffield F, Miller CF, Skegg JL. In: Symposium Series on Immunobiological Standardisation. Basel : Karger, 1970: 141-5.

${ }^{25}$ Hannik CA, Cohen H. Pertussis experience in the Netherlands. In: International Symposium on Pertussis. Washington DC : US Government Printing Office, 1978: 279-82.

${ }^{2}$ Kulenkampff M, Schwartzman SJ, Wilson J. Neurological complications of pertussis inoculation. Arch Dis Child 1974; 49: 46-9.

${ }^{27}$ Stewart GT. Toxicity of pertussis vaccine : frequency and probability of reactions.J Epidemiol Community Health 1979; 33: 150-6.

${ }^{20}$ Baraff LJ, Cherry JD, Cody CI. Rates, nature and etiology of adverse reactions associated with DPT vaccine. Bethesda: National Institutes of Health, 1980. 